\title{
MONOLOGIA E DIALOGIA NO DISCURSO DE UMA PROFESSORA \\ DE LÍNGUA INGLESA EM UM CONTEXTO ESCOLAR DE EJA ${ }^{1}$
}

\author{
MONOLOGY AND DIALOGY IN THE DISCOURSE OF AN ENGLISH \\ TEACHER IN THE CONTEXT OF EJA
}

Luciane Kirchhof Ticks (UFSM)

lkirchhofticks@gmail.com

Patricia Streppel Hartemink (UFSM)

paty_streppel@hotmail.com

\begin{abstract}
RESUMO: Esta pesquisa tem como objetivo analisar o discurso de uma professora de língua inglesa, a fim de identificar como estão materializadas léxico-gramaticalmente as ações dialógicas e monológicas, por ela adotadas, durante o desenvolvimento de uma aula da modalidade do Ensino de Jovens e Adultos (EJA). Para analisar os dados, adotamos uma abordagem híbrida, fundamentada pelo conceito de dialogismo (BAKHTIN, 1981; 1986; SCOTT; MORTIMER; AGUIAR, 2005), procurando depreender as ações monológicas e dialógicas subjacentes ao discurso dessa professora, e salientando como essas ações são constituídas por significados ideacionais e interpessoais, com base na Linguística SistêmicoFuncional (HALLIDAY; MATTHIESSEN, 2014; FUZER; CABRAL, 2014). A análise revelou que a professora equilibra ações discursivas: a) monológicas (11 ocorrências), caracterizadas por restrições à mediação, materializadas pelo uso de declarações e de processos verbais e relacionais; b) dialógicas (11 ocorrências), ao dar voz aos alunos, por meio de perguntas, materializadas por processos mentais, as quais os levam à reflexão sobre os temas abordados.
\end{abstract}

PALAVRAS-CHAVE: dialogismo; representações de papéis sociais; Linguística SistêmicoFuncional; EJA.

ABSTRACT: This research aims at analyzing the discourse produced by an English Language teacher, to identify how dialogical and/or monological actions adopted by her are materialized lexicogrammatically during the development of a Youth and Adults Education (EJA) class. For the data analysis, we use a hybrid approach, based on the concept of dialogism (BAKHTIN, 1981; 1986; SCOTT; MORTIMER; AGUIAR, 2005), trying to identify monologic and dialogic actions underneath the teacher's discourse, and highlighting the ideational and interpersonal meanings based on the Systemic Functional Linguistics

\footnotetext{
${ }^{1}$ Este trabalho faz parte da dissertação de mestrado da segunda autora citada e foi financiado pela CAPES (Coordenação de Aperfeiçoamento Pessoal de Nível Superior do Brasil - Código de Financiamento 001).
} 
framework (HALLIDAY; MATTHIESSEN, 2014; FUZER; CABRAL, 2014). The analysis revealed that the teacher balances discursive actions are: a) monological (11 occurrences), characterized by restrictions in terms of mediation, by the use of declarations and verbal and relational processes; b) dialogical (11 occurrences), when the teacher gives the students chances to talk, by asking questions, materialized by mental processes, which invite them to reflect about the themes discussed.

KEYWORDS: dialogism; representation of social roles; Systemic Functional Linguistics; EJA.

\section{Introdução}

O presente trabalho objetiva identificar, descrever e analisar os recursos ideacionais e interpessoais que constituem o discurso de uma professora de língua inglesa da modalidade de Ensino de Jovens e Adultos (EJA), a fim de examinar como esses recursos materializam posições discursivas mais dialógicas e/ou mais monológicas durante uma de suas aulas. Para tanto, adotamos uma abordagem híbrida, fundamentada pelo conceito de dialogismo (BAKHTIN, 1981; 1986; SCOTT; MORTIMER; AGUIAR, 2005) e pela Linguística Sistêmico-Funcional (HALLIDAY; MATTHIESSEN, 2014; FUZER; CABRAL, 2014), com foco nos significados realizados por duas das metafunções da linguagem: ideacional e interpessoal. Vale ressaltar que esta pesquisa se debruça sobre o discurso da professora ao lançar mão das contribuições da LSF para analisar como se constituem léxicogramaticalmente as ações monológicas e dialógicas adotadas pela participante. O processo argumentativo desencadeado por esta professora, em interação com seus alunos em sala de aula, foi analisado previamente (HARTEMINK, 2021). Futuras pesquisas em relação às posições dialógicas ou monológicas adotadas pelos alunos ainda são necessárias.

Nesse sentido, a análise detalhada dos recursos linguísticos com foco nas duas metafunções contribui para o entendimento de como essas práticas monológicas e/ou dialógicas estão materializadas na linguagem. De outro modo, como estas estão representadas no discurso da professora, destacando os papéis sociais adotados e a natureza da interação estabelecida em uma aula de língua inglesa, inserida na modalidade EJA.

Essa pesquisa se justifica pela necessidade de investigações tanto teóricas quanto metodológicas em relação às práticas sociais e discursivas de ensino e de aprendizagem com o objetivo de analisar e interpretar o uso da linguagem em contextos escolares de EJA, haja 
vista que o reconhecimento e o entendimento sobre essa modalidade específica são pouco difundidos (VENTURA; BOMFIM, 2015).

\section{Fundamentação teórica}

\subsection{Dialogismo}

A noção de dialogismo foi, inicialmente, proposta e desenvolvida por Bakhtin (1981, 1986). Segundo o autor, "qualquer entendimento do discurso ou enunciado proferido é inerentemente responsivo, embora o grau dessa atividade varie extremamente"2 (BAKHTIN, 1986, p. 68, tradução nossa). Nesse sentido, partimos do pressuposto de que os indivíduos estão sempre em um constante diálogo com os outros por meio da linguagem. Em outras palavras, os textos escritos e orais, as interações, o discurso e a linguagem, de forma mais ampla, possuem uma natureza dialógica. Em um determinado diálogo, ainda que o ouvinte não manifeste discursivamente sua opinião, quando ele:

percebe e entende o significado (o significado linguístico) do discurso, ele assume simultaneamente uma atitude ativa e responsiva em relação a esse significado. Ele concorda ou discorda com tal significado (total ou parcialmente), aumenta-o, aplicao, prepara-o para sua execução e assim por diante. ${ }^{3}$ (BAKHTIN, 1986, p. 68, tradução nossa)

No sentido bakhtiniano, o dialogismo implica uma relação social ativa, responsiva, participativa e contínua. Ademais, processos dialógicos pressupõem conflito, negociação de significados e exposição de diferentes pontos de vista, de acordo com as várias orientações ideológicas dos participantes ao longo de uma interação.

No entanto, os discursos podem divergir quanto à forma e ao grau em que o dialogismo se manifesta, uma vez que os participantes de uma interação podem adotar uma postura mais dialógica ou mais monológica. No âmbito educacional, Scott, Mortimer e Aguiar (2005) traçam a distinção entre essas duas posições discursivas do professor. Pautados nos conceitos de discurso autoritário e discurso internamente persuasivo, desenvolvidos por Bakhtin (1981), os autores afirmam que “o discurso dialógico está aberto a diferentes

\footnotetext{
${ }^{2}$ No original: "any understanding of live speech, a live utterance, is inherently responsive, although the degree of this activity varies extremely."

${ }^{3}$ No original: "when the listener perceives and understands the meaning (the language meaning) of speech, he simultaneously takes an active, responsive attitude toward it. He either agrees or disagrees with it (completely or partially), augments it, applies it, prepares for its execution, and so on."
} 
perspectivas" ${ }^{\prime 4}$ (SCOTT; MORTIMER; AGUIAR, 2005, p. 610, tradução nossa), ao passo que o discurso autoritário se caracteriza com um discurso monológico, pois "está fechado para os pontos de vista dos outros e a sua direção é definida antecipadamente pelo professor",

Mateus (2016) descreve algumas condutas dialógicas que o professor pode adotar, partindo do pressuposto de que estas "valorizam e legitimam a diferença, a empatia e a disposição para transformar" (MATEUS, 2016, p. 51). Dentre as orientações mencionadas pela autora, salientamos as seguintes: a) examinar os diferentes posicionamentos; b) considerar todas as vozes como legítimas; c) garantir a participação de todos; d) estar empenhado na ampliação das perspectivas e no entendimento de possibilidades alternativas; e) revisar seus próprios posicionamentos; e f) valorizar a diferença. A partir disso, ao estabelecer um cenário dialógico, o docente deve acolher tanto opiniões convergentes quanto divergentes, uma vez que a concepção de dialogismo pode ser entendida "como uma abordagem epistemológica do discurso que tem como foco os modos como negociamos e damos sentidos a diferentes ideologias e posicionamentos culturais" (MATEUS, 2016, p. 42).

Em contrapartida, na medida em que não há colaboração entre os participantes em sala de aula, a argumentação abre espaço para práticas e discursos monológicos. De Chiaro e Leitão (2005) mencionam três aspectos que podem dificultar a instauração da argumentação e corroborar condutas monológicas: 1) o caráter canônico dos temas discutidos em sala de aula; 2) a relação assimétrica entre professor e aluno; e 3) a determinação prévia em relação às conclusões de discussões.

Em relação ao primeiro ponto, as autoras afirmam que, muitas vezes, alguns temas e conteúdos curriculares são concebidos como conhecimentos legitimados e convencionalizados, restringindo a possibilidade de tornar tais tópicos polemizáveis (DE CHIARO E LEITÃO, 2005, p. 351). No que concerne à segunda questão, em alguns casos, o professor pode se apresentar como autoridade, em uma posição superior hierarquicamente em sala de aula. Consequentemente, seu engajamento nas discussões em aula tem como objetivo principal induzir os alunos "à aquisição de conceitos, formas de raciocínio e princípios considerados canônicos num certo domínio do conhecimento, não estando suas próprias perspectivas sobre os temas discutidos sujeitas à mudança" (DE CHIARO E LEITÃO, 2005, p. 351). Por fim, quanto ao último aspecto, a determinação prévia das conclusões, as possibilidades de desenvolver atividades argumentativas tendem a ser reduzidas, pois alguns

\footnotetext{
${ }^{4}$ No original: "dialogic discourse is open to different perspectives."

${ }^{5}$ No original: "authoritative discourse is closed to the points of view of others, with its direction having been set in advance by the teacher."
} 
dos conteúdos curriculares compreendem noções científicas que são ratificadas e validadas dentro de suas respectivas áreas do conhecimento. Além disso, esses conteúdos curriculares são, na maioria das vezes, definidos pelos professores, instituições ou, em última instância, por documentos legais e bases curriculares a nível nacional.

A fim de caracterizarmos essas posições monológicas e dialógicas adotadas pela participante desta pesquisa, elencamos algumas práticas pedagógicas típicas de sala de aula (Quadro 1), com base na perspectiva argumentativa, de acordo com Mateus (2016, p. 51), De Chiaro e Leitão (2005) e Leitão (2011).

\begin{tabular}{|l|l|}
\hline \multicolumn{1}{|c|}{ Práticas dialógicas } & \multicolumn{1}{c|}{ Práticas monológicas } \\
\hline $\begin{array}{l}\text { Superação da visão de ensino como reprodução } \\
\text { e memorização }\end{array}$ & Estímulo à visão de ensino como reprodução e memorização \\
\hline Estímulo a participação de todos & Restrição da medicação e interação \\
\hline Análise dos diferentes posicionamentos & Determinação prévia e/ou supressão de posicionamentos \\
\hline Estímulo/utilização da língua alvo & Fornecimento de traduções \\
\hline Legitimação de pontos de vista & Defesa do caráter canônico dos temas discutidos \\
\hline
\end{tabular}

Quadro 1 - Práticas dialógicas e monológicas

Fonte: autoria própria, com base em Mateus (2016, p. 51); De Chiaro e Leitão (2005) e Leitão (2011)

Partindo desses pressupostos, o intuito desta pesquisa é analisar os recursos ideacionais e interpessoais em discursos de uma professora de língua inglesa a fim de verificar como estes materializam o dialogismo estabelecido por ela. Para tanto, consideramos as contribuições da Linguística Sistêmico-Funcional como ferramenta teórico-metodológica, discutidas na próxima seção.

\subsection{Linguística Sistêmico-Funcional}

Sob a perspectiva da Linguística Sistêmico-Funcional (HALLIDAY; MATTHIESSEN, 2014), a linguagem é concebida como um fenômeno funcional e social. A dimensão funcional está associada às funções e significados que a linguagem desempenha em situações sociais específicas (FUZER; CABRAL, 2014). Em contrapartida, o caráter social diz respeito à estrutura social, isto é, ao ambiente sócio-histórico-cultural em que as pessoas que produzem linguagem estão inseridas (HALLIDAY, 1989).

Halliday e Matthiessen (2014, p. 3) definem a linguagem como um mecanismo para a construção de significados e o texto, por sua vez, como o processo dessa construção em contextos específicos. Logo, a linguagem é realizada em textos, por meio de escolhas que os 
usuários fazem para que possam atingir seus objetivos em diferentes situações comunicativas. Levando em consideração essa relação entre linguagem, texto e contexto, Halliday (1989) discute os conceitos de contexto de cultura e contexto de situação.

O contexto de cultura é uma organização ampla, pois está associado ao ambiente cultural de uma sociedade e as práticas em que seus membros estão engajados e inclui práticas sociais, valores, crenças, normas, regras e ideias que um grupo de pessoas compartilha (HALLIDAY, 1989). Por outro lado, o contexto de situação está relacionado ao ambiente mais imediato dos textos, isto é, o ambiente situacional em que os textos são produzidos.

Nesse enfoque sistêmico-funcional, Halliday (1989) propõe um modelo conceitual, baseado em três variáveis do contexto de situação: campo, relações e modo. Esse modelo contribui para as descrições de contextos de situação específicos, uma vez que estes podem motivar o significado dos textos (FUZER, 2010). O campo está associado à natureza da atividade que está acontecendo, aos acontecimentos que estão ocorrendo em uma situação específica, realizada por meio da linguagem. A variável relações está direcionada aos participantes que estão envolvidos nessa atividade, suas relações, interações e papéis sociais. Por fim, o modo está vinculado à organização do texto e sua função (HALLIDAY, 1989). Relações, campo e modo realizam respectivamente as três metafunções da linguagem: interpessoal, ideacional e textual. A seguir, detalhamos as duas primeiras metafunções, que se constituem como foco desta investigação.

\subsubsection{Metafunção interpessoal}

A análise da metafunção interpessoal pode contribuir para a compreensão dos papéis sociais desempenhados pelos participantes em uma interação e as relações sociais estabelecidas entre eles. Dessa forma, de acordo com essa metafunção, a oração ${ }^{6}$ é concebida como troca de bens e serviços ou de informações.

Durante um evento interativo, os participantes adotam determinados papéis de fala. Segundo Halliday e Matthiessen (2014), há dois papéis fundamentais da fala: dar e solicitar. Ademais, há dois tipos de comodidades que podem ser trocadas nessa interação: bens e serviços ou informações. Na troca de bens ou serviços, o valor a ser negociado se refere a uma ação, atividade ou objeto, ou seja, o produto de troca é estritamente não-verbal. Nesse caso, a

\footnotetext{
${ }^{6}$ Diferentemente da Gramática Tradicional, a Linguística Sistêmico-Funcional define a oração como unidade gramatical plurifuncional, isto é, ela é sistematizada de acordo com determinada metafunção (ideacional, interpessoal ou textual).
} 
função da oração é a proposta. Na troca de informações, por sua vez, o valor a ser negociado é a própria informação, isto é, a linguagem. Logo, a função da oração é a proposição. Essas duas variáveis determinam as quatro funções semânticas de fala: oferta, comando, declaração e pergunta, como sistematiza o Quadro 2:

\begin{tabular}{|l|l|l|}
\hline \multirow{2}{*}{ Papel na troca } & \multicolumn{2}{c|}{ Valor trocado } \\
\cline { 2 - 3 } DAR & INFORMAÇÕES & BENS E SERVIÇOS \\
\hline SOLICITAR & DECLARAÇÃO & OFERTA \\
\hline & PERGUNTA & COMANDO \\
\hline
\end{tabular}

Quadro 2 - Funções de fala com exemplos do corpus

Fonte: autoria própria, adaptado de Fuzer e Cabral (2014, p. 105), com base em Halliday e

Matthiessen (2004)

Os sistemas de realização léxico-gramatical da metafunção interpessoal são o Sistema de MODO e os Sistemas de Modalidade e Polaridade. No Sistema de MODO, podemos classificar a oração em dois componentes principais: Modo (Sujeito e Finito) e Resíduo (Predicador, Complemento e possíveis Adjuntos). O Sistema de Modalidade se refere ao “julgamento do falante ou solicitação de julgamento do ouvinte sobre o status do que está sendo dito"7 (HALLIDAY; MATTHIESSEN, 2014, p. 172, tradução nossa). Já o Sistema de Polaridade se refere à "oposição entre positivo e negativo"» (HALLIDAY; MATTHIESSEN, 2014, p. 172, tradução nossa). Em outras palavras, a polaridade pode ser expressa por meio de orações afirmativas ou negativas. O foco deste estudo será o Sistema de MODO, mais especificamente, os papéis e funções de fala, uma vez que a análise desses elementos contribui para o entendimento das posições discursivas (monológicos e/ou dialógicos) assumidas pela professora.

\subsubsection{Metafunção ideacional}

Ao focalizarmos a metafunção ideacional, podemos construir e representar a experiência humana por meio da linguagem (HALLIDAY; MATTHIESSEN, 2014). Essa metafunção é subdivida em duas subfunções: a experiencial e a lógica. A primeira é responsável pela construção da nossa interpretação experiencial; e sua unidade analítica é a oração. Já a última é responsável pela sequência lógica de figuras em uma configuração

\footnotetext{
${ }^{7}$ No original: "the speaker's judgement, or request of the judgement of the listener, on the status of what is being said."

${ }^{8}$ No original: "the opposition between positive and negative".
} 
experiencial de elementos, isto é, "combinações de grupos lexicais e oracionais" (FUZER; CABRAL, 2014); sua unidade analítica é o complexo oracional.

O foco deste trabalho é a subfunção experiencial. Nessa subfunção, consideramos a oração como representação por meio do sistema de transitividade. O sistema de transitividade "fornece recursos léxico-gramaticais para construção de um quantum de mudança no fluxo de eventos como uma figura" (HALLIDAY; MATTHIESSEN, 2014, p. 213), em que essa figura pode apresentar diferentes naturezas: acontecer, fazer, sentir, dizer, ser ou ter. Todas as figuras da linguagem são compostas por "um processo ${ }^{9}$ que se desdobra ao longo do tempo e participantes que estão diretamente envolvidos nesse processo de alguma forma" (HALLIDAY; MATTHIESSEN, 2014, p. 213). Ademais, essas figuras podem apresentar circunstâncias de tempo, espaço, causa, maneira, entre outras. Participantes são tipicamente realizados por grupos nominais, processos por verbos ou grupos verbais, e circunstâncias por elementos adverbiais, tais como tempo e espaço.

Considerando que o sistema de transitividade oferece meios para construir "um quantum de mudança no fluxo de eventos como uma figura" (HALLIDAY; MATTHIESSEN, 2014 , p. 213), os elementos que compõem essa figura serão configurados de acordo com o processo em evidência. Logo, podemos concluir que os processos são o ponto de partida da oração, concebida a partir da análise segundo o sistema de transitividade. Tão importantes quanto os processos, os participantes e circunstâncias das orações também colaboram para a identificação da natureza da oração. Entretanto, os processos determinam o "modelo ou esquema distinto para a construção de um domínio particular de experiência como uma figura de um tipo particular" (HALLIDAY; MATTHIESSEN, 2014, p. 213).

Os processos podem ser divididos em: a) principais - materiais, mentais e relacionais; e b) secundários - comportamentais, verbais e existenciais. Os processos materiais se referem a ações concretas dos indivíduos ou verbos que ilustram acontecimentos de determinados eventos. Os processos mentais, diferentemente dos materiais, estão associados à "experiência do mundo da nossa própria consciência"10 (HALLIDAY; MATTHIESSEN, 2014, p. 245, tradução nossa), isto é, às nossas experiências psicológicas. Eles se subdividem em quatro tipos: cognitivos (se referem ao pensamento), perceptivos (se referem à percepção em termos dos cinco sentidos), emotivos (se referem às emoções e sentimentos) e desiderativos (se

\footnotetext{
${ }^{9}$ No âmbito da Linguística Sistêmico-Funcional, os processos são o ponto de partida das orações, uma vez que todas as relações entre os componentes linguísticos que constituem as orações são estabelecidas a partir dos processos. Os processos indicam eventos, isto é, "atividades humanas realizadas no mundo" (FUZER; CABRAL, 2014, p. 27).

${ }^{10}$ No original: "experience of the world of our own consciousness".
} 
referem ao desejo e a vontade). Os processos relacionais estão relacionados ao ato de ser/estar e servem para caracterizar ou identificar algo ou alguém. Eles são subdivididos em dois tipos: atributivos (caracterizam algo ou alguém) e identificadores (identificam algo ou alguém).

Dentre os processos secundários, chamados "processos de fronteira" (ver Figura 1), encontram-se os processos comportamentais, verbais e existenciais. Os processos comportamentais se referem às ações do comportamento fisiológico e psicológico (tipicamente humano). Os processos verbais se referem aos processos de fala. Por fim, os processos existenciais "representam algo que existe ou que acontece"11 (HALLIDAY; MATTHIESSEN, 2014, p. 307, tradução nossa). A Figura 1 (adaptada de Cabral, 2002, com base em Halliday, 1994) ilustra os tipos de processos em um esquema circular com tons distintos em cada processo.

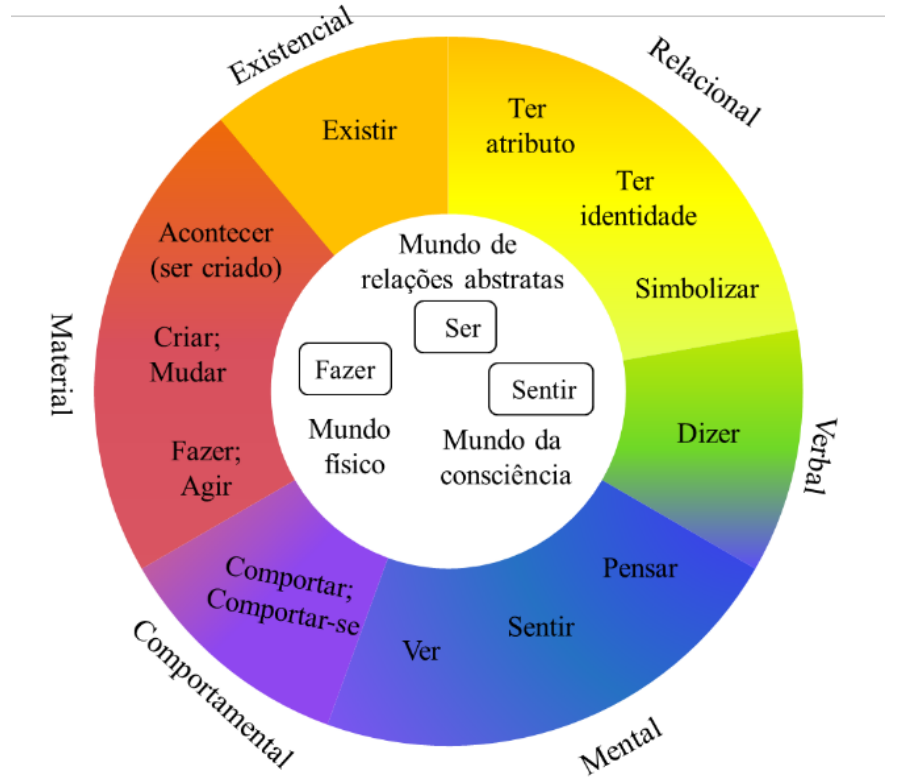

Figura 1 - Tipos de processos

Fonte: autoria própria, com base em Cabral (2002) e Halliday (1994)

Como podemos observar na Figura 1, os tipos de processos do sistema de transitividade são ordenados em forma circular contínua, uma vez que eles não constituem uma linha finita em que um processo se sobrepõe aos outros. Nessa direção, Halliday e Matthiessen destacam que dentro do sistema de transitividade "não há prioridade de um tipo de processo sobre outro (...) eles formam um círculo e não uma linha" (HALLIDAY; MATTHIESSEN, 2014, p. 216). Partindo da premissa de que os tipos de processos são

\footnotetext{
${ }^{11}$ No original: "represent that something exists or happens". 
organizados como um diagrama circular, as cores utilizadas para identificar cada um deles apresentam diferentes tonalidades, compondo uma sequência de tons contínuos que suavizam a transição entre esses processos. Dessa forma, os processos formam categorias difusas e podem se misturar, adquirindo características dos processos contíguos.

Assim, quando analisamos o discurso de uma professora de língua inglesa em sala de aula, focalizando o sistema de transitividade, buscamos entender como essa professora representa discursivamente suas práticas de ensino. Em última instância, procuramos identificar como se materializam, na linguagem, posições mais dialógicas ou mais monológicas.

\section{Metodologia}

Este estudo está fundamentado pela pesquisa crítica de colaboração (PCCol). A PCCol é uma abordagem da caráter qualitativo, reflexivo e crítico, pois objetiva promover espaços para construção conjunta de significados a fim de ressignificar as práticas sociais de um determinado contexto de pesquisa (MAGALHÃES, 2010). Nesse sentido, professora e alunos de uma turma de EJA se dispuseram a participar desta investigação, possibilitando que observássemos e registrássemos o processo interativo por eles estabelecido, como parte das ações de um programa de formação continuada que, em última instância, buscava problematizar o ensino multiletrado de língua inglesa no contexto da EJA (BRUM, 2019).

O corpus desta pesquisa é composto por uma atividade que integra uma aula de língua inglesa, gravada em 06/04/2018, em Santa Maria, RS/Brasil, e posteriormente transcrita. Ao total, a gravação da atividade durou $7 \min 29$ s. Optamos pelos procedimentos de gravação e transcrição das aulas, uma vez que estes conferem legitimidade e veracidade aos dados coletados. Em outras palavras, “o vídeo (filmagem) é indicado para estudo de ações humanas complexas difíceis de serem integralmente captadas e descritas por um único observador" (PINHEIRO; KAKEHASHI; ANGELO, 2005, p. 718). A atividade em questão abordava a temática "mercado de trabalho", explorando o conhecimento prévio dos alunos acerca de diferentes práticas usadas para procurar emprego. Segundo Rojo (2004), as atividades que exploram essa competência buscam dar voz aos alunos, que podem colaborar trazendo seu conhecimento de mundo acerca do assunto investigado. Nesse sentido, podemos dizer que podem contribuir para instaurar interações tipicamente dialógicas entre professora e alunos. Vale ressaltar que essa atividade, escolhida para fins analíticos, é um recorte do corpus que compõe a dissertação da primeira autora. 
Os participantes desse estudo são a professora de língua inglesa e seus respectivos alunos da EJA ${ }^{12}$, de uma escola pública de Santa Maria. Reforçamos que o foco desta análise recai sobre o discurso da professora, uma vez que o objetivo desse artigo é analisar como seu discurso materializa posições dialógicas ou monológicas ao interagir com seus alunos em uma atividade de língua inglesa da EJA. Para uma análise mais detalhada acerca do processo argumentativo estabelecido entre professora e alunos, ver Hartemink (2021). Em relação aos procedimentos analíticos, a investigação envolveu as seguintes etapas: a) transcrição da atividade; b) análise do discurso da professora, procurando mostrar como os significados interpessoais e ideacionais constituem as posições monológicas e/ou dialógicas, discutidas na revisão da literatura, vivenciadas em sala de aula.

\section{Resultados e discussão}

Neste capítulo, apresentamos a análise do corpus e procuramos mostrar que a participante adota equilibradamente posições discursivas monológicas (11 ocorrências) e dialógicas (11 ocorrências) (Tabela 1, Anexo 1). Entre as práticas monológicas mais recorrentes, destacamos o Fornecimento de Traduções e, entre aquelas consideradas dialógicas, evidenciamos uma recorrência maior da Legitimação de Pontos de Vista.

\begin{tabular}{|c|c|c|c|}
\hline Práticas monológicas & N.O & Práticas dialógicas & $N . O$ \\
\hline $\begin{array}{c}\text { Estímulo à visão de ensino como } \\
\text { reprodução e memorização (ERM) }\end{array}$ & 1 & $\begin{array}{c}\text { Superação da visão de ensino como reprodução e } \\
\text { memorização (SRM) }\end{array}$ & 2 \\
\hline $\begin{array}{c}\text { Restrição da medicação e interação } \\
\text { (RMI) }\end{array}$ & 2 & Estímulo a participação de todos (EPT) & 2 \\
\hline $\begin{array}{c}\text { Determinação prévia e/ou supressão de } \\
\text { posicionamentos (DPP) }\end{array}$ & 3 & Análise dos diferentes posicionamentos (ADP) & 2 \\
\hline Fornecimento de traduçães (FT) & 5 & Estímulo/utilização da língua alvo (ELA) & 2 \\
\hline $\begin{array}{c}\text { Defesa do caráter canônico dos temas } \\
\text { discutidos (DCC) }\end{array}$ & 0 & Legitimação de pontos de vista (LPV) & 3 \\
\hline TOTAL & 11 & TOTAL & 11 \\
\hline
\end{tabular}

Tabela 1 - Identificação e número de ocorrências (N.O) das práticas monológicas e dialógicas

Fonte: autoria própria

Após essa análise prévia inicial, procuramos evidenciar as características léxicogramaticais que materializam essas ações, com base nas categorias propostas nas metafunções interpessoal (Seção 4.1) e ideacional (Seção 4.2).

\footnotetext{
${ }^{12}$ Esta pesquisa está amparada pelo Comitê de ética da Universidade Federal de Santa Maria, registrada sob o número 44567315.3.0000.5346.
} 


\subsection{Metafunção interpessoal}

Por meio da análise do sistema de MODO, mais especificamente, da organização dos papéis e das funções de fala, foi possível evidenciar duas representações do papel que a professora assume em aula: ora professora monológica, ora professora dialógica. O primeiro papel é realizado semântica e lexicalmente por meio de declarações ao fornecer traduções aos alunos e comandos ao usar o imperativo e, dessa forma, restringir a mediação e a interação em sala de aula. Em outras palavras, a professora "dá informações" por meio da função semântica de declaração (exemplo 1) e "solicita bens e serviços" por meio da função semântica de comando (exemplo 2).

\begin{tabular}{|l|l|}
\hline Exemplo 1 & Magazines é revistas. \\
\hline & Dar informações - Declaração \\
\hline & Fornecimento de tradução \\
\hline
\end{tabular}

\begin{tabular}{|l|l|}
\hline Exemplo 2 & Mas não se demorem muito. \\
\hline & Solicitar bens e serviços - Comando \\
\hline & Restrição da mediação e interação \\
\hline
\end{tabular}

No exemplo 1, a professora fornece informações por meio de uma declaração, especificamente a traduções de uma das opções do exercício. Nesse sentido, essa prática da tradução dos termos materializa esse papel monológico, em que ela não estimula a participação dos alunos a fim de alcançar uma construção conjunta das noções envolvidas na questão. Tal categoria de "fornecimento de traduções" foi a mais recorrente no corpus, pois totalizou 5 ocorrências. Sua realização ocorre em momentos em que os alunos solicitam informações pontuais sobre as definições de termos e alternativas da questão e a professora, por sua vez, fornece traduções como respostas às perguntas feitas pelos alunos. Por outro lado, no exemplo 2, a professora "solicita serviços" dos alunos por meio de um comando, ao demandar que eles não demorem muito tempo no processo de assinalar a questão correta. Nesse caso, ao utilizar esse comando, a professora automaticamente restringe a interação entre os alunos, pois comandos possuem uma natureza monológica, uma vez que são tipicamente realizados por um processo que manifesta uma ordem. Em relação ao papel dialógico, sua realização ocorre por meio da função semântica de pergunta - solicitação de informações (exemplo 3), mais especificamente, quando a professora visa engajar os alunos, por meio de uma pergunta, para que eles analisem os significados em questão. 


\begin{tabular}{|l|l|}
\hline Exemplo 3 & Vocês conseguem entender [a pergunta]? \\
\hline & Solicitar informações - Pergunta \\
\hline & Análise dos diferentes posicionamentos \\
\hline
\end{tabular}

No exemplo 3, a professora assume o papel dialógico de solicitante de informações, ao passo que propõe aos alunos o papel de "fornecedores da informação demandada" (HALLIDAY; MATTHIESSEN, 2014, p. 134). Ao usar a função semântica de pergunta, a professora visa buscar o entendimento destes em relação à questão proposta anteriormente. A realização dessa função semântica ocorre, normalmente, quando a professora desencadeia o processo de realização da questão, isto é, ao contextualizar a questão e demandar dos alunos suas percepções. Ao contrário dos exemplos 1 e 2, em que a professora fornece traduções e limita a participação e construção colaborativa de significados, neste exemplo (exemplo 3), a professora reconhece as possíveis compreensões dos alunos, considerando-os como sujeitos capazes de opinar sobre a questão proposta. Essa prática propicia aos alunos um processo de reflexão, construção e produção de sentidos por meio da pergunta que a professora faz.

Nesse enfoque, o ato de perguntar "implica oferecer oportunidades para que o outro manifeste seu pensamento, fruto de sua visão de mundo, produto de suas experiências individuais e socioculturais a serem compartilhadas (...)” (NININ, 2018 p. 25). Similarmente, Mateus (2016, p. 37) afirma que "perguntas têm poder não porque provocam respostas, mas na medida em que valorizam aqueles que respondem e fomentam suas possibilidades de gerar novas perguntas". Logo, a pergunta, nesse contexto, serve como um recurso para engajar os alunos e reconhecer, considerar e legitimar suas concepções e interpretações acerca da questão.

\subsection{Metafunção ideacional}

Outro fator que contribui para os papéis que a professora assume em aula é a análise do sistema de transitividade. A representação do papel de professora monológica é léxicogramaticalmente realizada pelos processos verbais e relacionais no corpus (exemplos 4 e 5), que expressam a prática prescritiva, realizada pela professora, de ler e traduzir os enunciados.

\begin{tabular}{|l|l|l|l|l|}
\hline \multirow{2}{*}{ Exemplo 4} & {$[\mathrm{Eu}]$} & vou traduzindo & [as questões] & conforme vocês tiverem dificuldade. \\
\cline { 2 - 5 } & Dizente & Processo verbal & Verbiagem & Circunstância de Contingência: Condição \\
\hline
\end{tabular}




\begin{tabular}{|l|l|l|l|}
\hline Exemplo 5 & Looking for & [é] & procurar. \\
\cline { 2 - 4 } & Identificado & Processo relacional identificador & Identificador \\
\hline & \multicolumn{2}{|l}{ Fornecimento de tradução } \\
\hline
\end{tabular}

A postura monológica é realizada, mais especificamente, no discurso da professora, pelo processo verbal "traduzir" e pelo processo relacional "é". O primeiro processo demonstra um estímulo à visão de ensino como reprodução e memorização, em que a aula é centrada somente na professora, que "lê e traduz" os enunciados das questões. Como afirma Ryckebusch (2016, p. 118), "se a centralidade das decisões, os procedimentos de trabalho e as expectativas do que se quer ensinar-aprender forem mantidos nas mãos dos professores, manter-se-á o cerceamento à participação e à formação crítica e reflexiva dos alunos". Dessa forma, no momento em que a professora preestabelece a sistemática da aula, ela também preestabelece os papéis a serem assumidos: a docente conduz a aula e transmite os conteúdos, informações e traduções enquanto os alunos fornecem as respostas.

Por conseguinte, o segundo processo manifesta o ato de tradução dos termos em inglês, enfatizando, mais uma vez, o método de tradução que a professora utiliza durante a aula. Vale ressaltar que, como mencionamos anteriormente, os processos relacionais identificadores são predominantes no corpus e indicam, em diversos momentos, essa prática de tradução das palavras, que é realizada pela categoria de "fornecimento de informações e, neste caso, de traduções”. Como Halliday e Matthiessen (2014, p. 277) afirmam, os processos relacionais identificadores servem para construir conhecimento ao fornecer definições, interpretar evidências e estabelecer unicidade, nomes e termos técnicos. Entretanto, nesse caso, a professora fez uso dos processos relacionais apenas para fins de tradução da língua alvo para a materna em detrimento da possibilidade da compreensão conjunta de significados pelos participantes (professora e alunos). Por fim, a realização lexical dessas traduções no sistema de transitividade corresponde ao uso da função semântica de declaração, no sistema de MODO. Logo, a associação das declarações e uso de processos relacionais identificadores evidencia no corpus o papel de professora monológica. Por outro lado, a segunda representação se refere à postura dialógica que a professora adota. Essa concepção é realizada pelos processos mentais, que indicam as capacidades cognitivas dos alunos em relação ao que será abordado em aula (exemplo 6). 


\begin{tabular}{|l|l|l|l|}
\hline Exemplo 6 & {$[$ Vocês] } & conhecem & as palavras? \\
\cline { 2 - 4 } & Experienciador & Processo mental cognitivo & Fenômeno \\
\hline & Análise dos diferentes posicionamentos \\
\hline
\end{tabular}

No exemplo 6, a professora solicita informações dos alunos, utilizando o processo mental cognitivo "conhecer". Ao usar esse processo, ela demanda um retorno dos alunos (Experienciadores) em relação ao fenômeno de conhecimento deles (HALLIDAY; MATTHIESSEN, 2014, p. 246), isto é, suas compreensões e interpretações sobre as palavras (Fenômeno).

Pode-se observar que, em todos os casos em que a professora utiliza processos mentais, sua fala é realizada pela função semântica de pergunta - solicitação de informações, de acordo com sistema de MODO e pela categoria dialógica de "análise dos diferentes posicionamentos". Logo, a relação das análises segundo as metafunções interpessoal e ideacional colabora, conjuntamente, para a construção desse papel dialógico que a professora assume. As perguntas, conforme supracitado na seção de resultados da análise realizada de acordo com o sistema de MODO (seção 4.2), têm um grande potencial dialógico, pois "podem ser entendidas como um diálogo argumentativo" (NININ, 2016, p. 178) em momentos em que a professora busca mediar a participação dos alunos por meio dessas perguntas que buscam fazer o aluno refletir sobre os temas abordados. Ademais, por meio do sistema de transitividade, podemos notar que a professora utiliza processos mentais cognitivos ao formular essas perguntas (exemplos 3 e 6). Esse fator amplia a natureza dialógica das perguntas, uma vez que os processos mentais cognitivos expressam a consideração da professora em relação ao julgamento, à interpretação, à análise do processo reflexivo dos alunos. Exemplificando, uma pergunta que utiliza um processo material (Qual [alternativa] que vocês marcaram então ${ }^{13}$ ) possui um grau dialógico menor do que uma pergunta que utiliza um processo mental cognitivo (Vocês conseguem entender [a pergunta]?).

Apesar de um número menor de ocorrências dos processos mentais, podemos observar a tentativa da professora em desenvolver uma abordagem dialógica ao questionar os alunos sobre o conhecimento que estes possuem e propiciar um ambiente de interação e troca.

\section{Considerações finais}

Em síntese, por meio da associação dos dados analisados com base nas duas

\footnotetext{
${ }^{13}$ Exemplo retirado do corpus. 
metafunções, identificamos duas representações equilibradas de papéis sociais desempenhados pela professora: monológico (11 ocorrências) e dialógico (11 ocorrências). A conduta monológica é realizada por ações que restringem a participação dos alunos, materializadas por processos verbais e relacionais, no Sistema de Transitividade; comandos e declarações, nas Funções de Fala. Em contrapartida, a conduta dialógica é realizada por ações que dão voz aos alunos, levando-os à reflexão, por meio de processos mentais, no Sistema de Transitividade; e uso de perguntas, nas Funções de Fala.

Vale ressaltar que o papel mediador da professora é essencial, pois "o engajamento dos alunos no processo reflexivo de revisão de perspectivas depende de ações discursivas específicas do docente: do seu estímulo à formulação de pontos pelos alunos (...)" (LEITÃO; CASTRO, 2016, p. 168). Logo, uma vez que a função mediadora da professora é limitada, a produção e a expansão de conhecimentos se tornam restritas, e as capacidades problematizadoras e críticas dos alunos não são exploradas ou desenvolvidas. Contudo, apesar de uma menor parcela relativa à representação do papel de professora dialógica, podemos observar sua tentativa em desenvolver essa abordagem ao questionar os alunos sobre o conhecimento que eles possuem e buscar, em alguns momentos, propiciar um ambiente de interação e troca.

Por fim, em relação ao contexto de pesquisa em que este estudo foi realizado, a saber, o âmbito da EJA, apontamos a necessidade de mais pesquisas que aprofundem o entendimento dessa modalidade (BRUM, 2019), uma vez que investigações que englobam tal contexto ainda são limitadas. Tais estudos poderiam jogar luz sobre a) as práticas sociais oriundas dessa modalidade; b) o reconhecimento da EJA como um espaço de formação; c) a necessidade de formação tanto inicial quanto continuada de professores atuantes nessa modalidade; d) a problematização de pedagogias que deem voz ao público que compõe a EJA e e) as reflexões acerca da inclusão dessa modalidade em documentos recentes como a BNCC. Dessa forma, sugerimos um maior aprofundamento teórico e metodológico dessa modalidade própria e específica da Educação Básica, a fim de que tais aspectos sejam referenciados e abordados em pesquisas da grande área de Linguística Aplicada.

\section{REFERÊNCIAS}

BAKHTIN, M. The Dialogical Imagination: Four Essays. Austin: University of Texas Press, 1981. 
BAKHTIN, M. Speech Genres \& Other Late Essays. Austin: University of Texas Press, 1986.

BRUM, M. H. Formação continuada de professores de língua inglesa: em busca de uma prática pedagógica multiletrada para a EJA. 2019. 269 f. Tese (Doutorado em Letras) Universidade Federal de Santa Maria, Santa Maria, 2019.

CABRAL, S. S. Estrutura textual e transitividade: a carta do leitor como construção da experiência. 2002. Dissertação (Mestrado em Letras) - Universidade Federal de Santa Maria, Santa Maria, 2002.

DE CHIARO, S.; LEITÃO, S. O Papel do Professor na Construção Discursiva da Argumentação em Sala de Aula. Psicologia: Reflexão e Crítica, São Paulo, v. 18, n. 3, p. 350357, 2005. Disponível em: http://www.scielo.br/pdf/prc/v18n3/a09v18n3.pdf. Acesso em: 28 mar. 2018.

FUZER, C. Contexto e léxico-gramática em interação: análise de uma sentença condenatória. Letras, Santa Maria, v. 20, n. 40, p. 113-132, jan./jun. 2010. Disponível em: http://cascavel.ufsm.br/revistas/ojs-2.2.2/index.php/letras/article/view/12147/7541. Acesso em: 5 ago. 2019.

FUZER, C.; CABRAL, S.R.S. Introdução à Gramática Sistêmico-Funcional em Língua Portuguesa. Campinas: Mercado de Letras, 2014.

HALLIDAY, M. A. K.. An Introduction to Functional Grammar. 3rd. ed. London: Arnold, 2004.

HALLIDAY, M. A. K.. An Introduction to Functional Grammar. 2nd. ed. London: Arnold, 1994.

HALLIDAY, M. Context of situation. In: HALLIDAY, M. A. K.; HASAN. R. Language, context, and text: Aspects of language in a social-semiotic perspective. Oxford: Oxford University, 1989. p. 3-14.

HALLIDAY, M. A. K.; MATTHIESSEN, C. M. I. M. Halliday's Introduction to Functional Grammar. New York/London: Routledge, 2014.

HARTEMINK, P. S. O processo argumentativo construído em um programa de formação continuada multiletrada com professores da educação de jovens e adultos (EJA). 2021. $303 \mathrm{f}$. Dissertação (Mestrado em Letras) - Universidade Federal de Santa Maria, Santa Maria, 2021.

LEITÃO, S. O lugar da argumentação na construção do conhecimento em sala de aula. In: LEITÃO, S.; DAMIANOVIC, M. C. (Org.). Argumentação na escola: o conhecimento em construção. Campinas: Pontes Editores, 2011.p. 13-46.

LEITÃO, S.; CASTRO, J. L. G. Argumentação de crianças do Primeiro Ano Fundamental sobre temas curriculares In: LIBERALI, F. C.; DAMIANOVIC, M. C.; NININ, M. O. G.; MATEUS, E.; GUERRA, M. (Org.). Argumentação em contexto escolar: relatos de pesquisa. Campinas: Pontes Editores, 2016. p. 205-237. 
MAGALHÃES, M. C. C. Pesquisa Crítica de Colaboração: uma pesquisa de intervenção no contexto escolar. In: SILVA, L. S. P.; LOPES, J. J. M. (Org.) Diálogos de Pesquisa sobre crianças e infâncias. Juiz de Fora: Ed. UFJF, 2010. p. 21-40.

MATEUS, E. Por uma pedagogia da argumentação. In: LIBERALI, F. C.; DAMIANOVIC, M. C.; NININ, M. O. G.; MATEUS, E.; GUERRA, M. (Org.). Argumentação em contexto escolar: relatos de pesquisa. Campinas: Pontes Editores, 2016. p. 35-61.

NININ, M. O. G. Da pergunta como ato monológico avaliativo à pergunta como espaço para expansão dialógica: uma investigação à luz da Linguística Aplicada sobre modo de perguntar. Campinas: Pontes Editores, 2018.

NININ, M. O. G. Padrões de colaboração e argumentação: uma perspectiva crítica para análise do desenvolvimento de educadores. In: LIBERALI, F. C.; DAMIANOVIC, M. C.; NININ, M. O. G.; MATEUS, E.; GUERRA, M. (Orgs.). Argumentação em contexto escolar: relatos de pesquisa. Campinas: Pontes Editores, 2016. p. 175-204.

PINHEIRO; E., M.; KAKEHASHI; T. Y.; ANGELO, M. O uso de filmagem em pesquisas qualitativas. Revista Latino-Americana de Enfermagem, Ribeirão Preto, v. 13, n. 5, p. 717722, set./out. 2005.

ROJO, R. Letramento e capacidades de leitura para a cidadania. São Paulo: SEE: CENP, 2004.

RYCKEBUSH, C. G. "Roda de conversa" na educação infantil: uma abordagem críticocolaborativa na produção de conhecimento. In: LIBERALI, F. C.; DAMIANOVIC, M. C.; NININ, M. O. G.; MATHEUS, E.; GUERRA, M. (Orgs.). Argumentação em contexto escolar: relatos de pesquisa. Campinas: Pontes Editores, 2016. p. 113-144.

SCOTT, P. H.; MORTIMER, E. F.; AGUIAR, O. G. The tension between authoritative and dialogic discourse: a key feature of meaning making interactions in secondary school science classrooms. Science Education, New York, v. 90, n. 7, p. 605-631, 2005.

VENTURA, J.; BOMFIM, M. I. Formação de Professores e Educação de Jovens e adultos: o formal e o real nas licenciaturas. Educação em Revista, Belo Horizonte, v. 2, n. 31, p. 211 227, 2015. Disponível em: http://www.scielo.br/pdf/edur/v31n2/0102-4698-edur-31-0200211.pdf. Acesso em: 5 ago. 2019.

Artigo submetido em: 14 abr. 2021 Aceito para publicação em: 11 jun. 2021 DOI: http://dx.doi.org/10.22456/2238-8915.113045 


\section{Anexo 1 - Excerto da aula de língua inglesa da EJA analisada}

\begin{tabular}{|c|c|}
\hline EXCERTO & SIGLA \\
\hline $\begin{array}{l}\text { Professora: Bom... Então, assim... As primeiras questões, até a número três ali, eu vou... Nós vamos } \\
\text { fazer juntos, certo? Eu vou ler as questões, vou traduzindo conforme vocês tiverem dificuldade e } \\
\text { vocês vão respondendo oralmente, tá? Depois nas próximas, eu dou um tempinho para vocês } \\
\text { tentarem analisar lá no texto, tá? Mas não se demorem muito. ERM RMI }\end{array}$ & ERM \\
\hline Todos: [risos] & - \\
\hline $\begin{array}{l}\text { Professora: Então vocês têm lá... No título, né: In the job market. Então, no mercado de trabalho. } \\
\text { Aí, looking for a job, no cartazinho [aponta para o cartaz na cópia], alguém procurando por } \\
\text { emprego, tá? Looking for, procurar, job, emprego. Certo? Procurando por emprego... E abre a } \\
\text { temática então... Mercado de trabalho. Certo? Aí vocês têm a primeira questão: Where do people } \\
\text { usually look for job? Aí, vocês conseguem entender? }\end{array}$ & ADP \\
\hline Aluno B: Onde é que trabalha quem? & - \\
\hline Professora: Whe-re-do-peo-ple usually lo-ok for-job (pausadamente)? & ELA \\
\hline Aluno C: Onde normalmente as pessoas procuram emprego. & - \\
\hline Professora: Good, exaclty! & LPV \\
\hline Aluno B: Aí sim! Tem um inglês aqui, professora! Que beleza! & - \\
\hline $\begin{array}{l}\text { Professora: [risos] Onde geralmente as pessoas procuram por emprego, tá? Aí nós temos as opções: } \\
\text { Magazines, directly at the companies, newspapers, book, internet... Or others e for example. } \\
\text { Algum... Algumas dessas opções vocês conhecem? Conhecem as palavras? }\end{array}$ & $\begin{array}{l}\text { ELA } \\
\text { ADP }\end{array}$ \\
\hline Aluna D: Book é livro, né? & - \\
\hline Professora: Book, livro, isso! & FT \\
\hline Aluno B: Lojas, né, magazines? & - \\
\hline Aluna A: Magazines. & - \\
\hline Professora: Magazines... Não... & SRM \\
\hline Aluno C: Revistas. & - \\
\hline Professora: (continuação) É! Isso! É um falso cognato. Magazines é revistas. Tá? Não é a loja. & SRM \\
\hline Aluno C: Newspaper é jornal? & - \\
\hline Professora: Newspaper, jornal. & FT \\
\hline Aluno B: E essa... essa... Essa aqui, book, essa aqui, seria o que? & - \\
\hline Professora: Book? Livro... Livro! Lembram: "the book is on the table"? & FT \\
\hline Aluno B: Sim, mas procurar trabalho em livro? & - \\
\hline Professora: Não, mas aí vocês vão escolher aonde geralmente (...) vocês vão marcar, tá? & DPP \\
\hline Aluno C: Marcar uma só? & - \\
\hline Professora: Pode ser mais de uma. & SRM \\
\hline Aluno C: Pode ser mais de uma. [confirmando]. & - \\
\hline Professora: Então vocês têm: magazines, revistas, directly at the companies... Diretamente nas...? & EPT \\
\hline Aluna D: Empresas. & - \\
\hline $\begin{array}{l}\text { Professora: Empresas! [enfática, confirmando a resposta] Newspapers, jornal, book, livro ou } \\
\text { internet. Aí vocês vão marcar qual é mais comum. Pode ser mais de uma, né. }\end{array}$ & $\begin{array}{l}\text { LPV } \\
\text { DPP }\end{array}$ \\
\hline Aluno B: Aquela ali é alguma outra opção? [se referindo à opção "others"] & - \\
\hline Professora: Isso, se houver outras opções de... De lugar pra se procurar, aí vocês podem marcar. & RMI \\
\hline Aluna E: E o new é o que? Newspaper? & - \\
\hline $\begin{array}{l}\text { Professora: Newspaper? Jornal! Jornal [professora faz uma pausa para que os alunos escolham as } \\
\text { opções enquanto alguns conversam entre si]. Qual que vocês marcaram então? Quais opções? }\end{array}$ & \begin{tabular}{|l|l|l} 
FT \\
EPT
\end{tabular} \\
\hline Aluna D: Direto nas empresas... & - \\
\hline Aluna A: E na internet. & - \\
\hline Aluna D: Jornal. & - \\
\hline Alunos em coro: Jornal e internet. & - \\
\hline Professora: Newspapers! Directly at the companies! Internet! Isso... que é ma & $\begin{array}{l}\text { LPV } \\
\text { DPP }\end{array}$ \\
\hline
\end{tabular}

\section{Práticas monológicas}

Práticas dialógicas 